\title{
Outcome analysis of patients with Peyronie's disease who elect for vacuum erection device therapy
}

\author{
Landan P. MacDonald ${ }^{1}$; M. Luke Armstrong ${ }^{1}$; Kyle J. Lehmann²; Matthew R. Acker ${ }^{1}$; \\ Gavin M. Langille ${ }^{1}$ \\ ${ }^{1}$ Department of Urology, Dalhousie University, Saint John, NB, Canada; ${ }^{2}$ Department of Urology, Dalhousie \\ University, Halifax, NS, Canada
}

Cite as: Can Urol Assoc J 2020 March 30; Epub ahead of print. http://dx.doi.org/10.5489/cuaj.6205

Published online March 30, 2020

$* * *$

\section{Abstract}

Introduction: Peyronie's disease (PD) affects approximately $0.7-11 \%$ of men ${ }^{1}$ and has numerous proposed treatments. Invasive management options include surgical or injectable therapy, while penile traction therapy with vacuum erection device (VED) represents a noninvasive approach. Our objective is to assess outcomes for patients with PD who opt for noninvasive management.

Methods: We performed a retrospective analysis for patients with PD who were followed for at least three months and opted for non-invasive therapy. All patients were instructed to initiate VED traction therapy for 10 minutes twice per day. Patients were assessed for degree of PD deformity and erectile function (Sexual Health Inventory for Men [SHIM] score) at initial and subsequent encounters.

Results: Fifty-three patients met the inclusion criteria. The mean (standard deviation [SD]) age was 57 (12) years, and the mean (SD) duration of PD prior to assessment was 25 (15) months. The mean (SD) duration of followup was 14 (11) months. Among untreated patients who did not use a VED, nine showed improvement, 20 remained stable, and four had worsening curvature. The untreated group had a significant change in curvature, with a mean improvement (SD) of 3.6 $(12)^{\circ}(\mathrm{p}=0.048)$. All 20 men who initiated VED traction therapy had an improvement in curvature with a significant mean (SD) improvement of $23(16)^{\circ}\left(\mathrm{p}=2.6 \times 10^{-6}\right)$. Changes in SHIM scores did vary significantly between groups. No complications were noted.

Conclusions: In patients who opt for non-invasive management of PD, VED traction therapy provides improved curvature resolution compared to those who do not use such a device. The 
limitations of this study include the retrospective nature and a small sample size at a single treatment center.

\section{Introduction}

Peyronie's disease (PD) is an acquired penile deformity due to fibrosis of the tunica albuginea. The etiology is incompletely understood, but is thought to involve a component of genetic predisposition and cavernosal trauma leading to fibrotic cascade. ${ }^{2-5}$ Prevalence estimates vary with definition, and range from $0.7 \%$ to $11 \%$ of men with peak incidence at 53 years of age. ${ }^{1,6}$ Physical symptoms may include penile pain, deformity, and erectile dysfunction (ED). ${ }^{7,8}$ Psychosocial symptoms may include emotional distress, depressive symptoms, and relationship difficulties. ${ }^{9,10}$ Furthermore, the natural history of untreated PD demonstrates spontaneous improvement in only $8-12 \%$ of cases, with the majority of cases stabilizing or showing progressive deformity. ${ }^{2,11}$

Surgical intervention has been the mainstay of treatment for refractory PD and includes plication or grafting with or without implantation of a penile prosthesis for ED. ${ }^{2,12}$ Invasive surgical treatments carry the risk of patient dissatisfaction, and penile shortening is associated with some techniques. ${ }^{2,13}$ Shortcomings of surgery drive the search for less invasive management options, including oral pharmacotherapy, intralesional injections, electromotive treatment, and mechanical therapies. ${ }^{5,8,12,14}$ Traction and vacuum erection devices (VED) are non-invasive options under study and may be a viable method of halting disease progression and possibly reversing pathological penile curvature. ${ }^{15,16}$ Penile traction in PD is hypothesized to work by the same mechanism as is known to be effective in the biologically similar Dupuytren's scar, where repeated traction lengthens the fibrinous plaque by reorganization of the extracellular collagen matrix. ${ }^{4,6,16}$

Despite its potential, there is a lack of evidence for VED therapy in PD. ${ }^{2,15}$ This study analyzes the effects of VED therapy, for 10 minutes twice-daily, on penile curvature and erectile function in men with PD compared to the untreated natural history. Through a single-center retrospective analysis of clinical data, this study assesses VED and potential impact on penile curvature and erectile function in men with PD compared to no treatment. VED may be an effective, safe, and non-invasive treatment option for PD with the potential to divert patients from more invasive treatments.

\section{Methods}

The cohort of male patients were assessed for PD between July 2014 and January 2018. At the time of initial assessment, patients were evaluated for potential treatment options including injectable therapy, surgical management, and non-invasive VED traction therapy. Patients were excluded from this study if they elected to undergo surgical or injectable management for PD. All patients were followed and managed accordingly as per their attending urologist. 
Patients who opted for conservative measures were asked to purchase the Osbon ErecAid Esteem $^{\mathrm{TM}}$ and to use the device for 10 minutes twice per day for at least 3 months. Raheem et al. (2009) also used 10 minute treatment times for VED therapy. ${ }^{15}$

Patient outcome variables including degree of penile curvature, degree of erectile dysfunction, and quality of life outcomes were assessed at the initial and subsequent patient encounters. The degree of penile curvature was estimated using a photograph and a protractor. We determined the statistical significance of the change in penile curvature using a student's t-test with $\alpha=0.05$ as the cutoff for significance. Table 1 summarizes the patient population for each group.

\section{Results}

A total of 53 patients were included in this study; 20 patients used VED traction therapy and 33 patients did not. The improvement in penile curvature for the untreated group was $3.6 \pm 12^{\circ}$. The VED group had an improvement in penile curvature of $23 \pm 16^{\circ}$. Table 2 shows the outcomes of measured variables. One patient in the untreated group had previously used verapamil gel for correction of his PD. The median duration of PD for the treatment group was 22.5 months.

We found the reduction in penile curvature to be statistically significant both for patients using VED traction therapy $\left(\mathrm{p}=2.6 \times 10^{-6}\right)$ and for untreated patients had a $(\mathrm{p}=0.048)$. When comparing the reduction between the two treatment groups, the VED group had more improvement of penile curvature $\left(\mathrm{p}=4.9 \times 10^{-6}\right)$.

The change in penile curvature as a function of patient age yielded a non-significant result. Initial penile curvature was significantly correlated to the reduction in penile curvature for all participants $(\mathrm{p}=0.0016)$. Meaning the larger the initial curvature, the larger the reduction in curvature.

There was no association between duration of PD and reduction of curvature. The average duration of PD for our groups was approximately 2 years, there were no patients who suffered from PD for $<6$ months.

The change in Sexual Health Inventory for Men (SHIM) ${ }^{17}$ score was recorded for each group; the increase in average score was larger in the VED group but was not statistically significant, however the untreated group had a significant reduction in SHIM score.

The effects of diabetes, smoking, hypertension, and dyslipidemia were taken account to determine their effects on VED therapy efficacy. There was no significant difference between groups who had the aforementioned characteristics in both groups.

\section{Discussion}

Due to the non-invasive nature and the minimal side-effect profile, VEDs have potential to be a safe and effective means of treatment. The majority urologists do not choose this treatment modality when surveyed ${ }^{18,19}$ likely due to the limited number of studies that have evaluated its effectiveness. Raheem et al. (2009) first published the use of a VED as non-invasive 
management of PD. This case series showed a clinically and statistically significant reduction of penile curvature with the use of a VED for 10 minutes twice daily for 31 patients. Patients with a soft, fleshy plaque had better results than others. Erectile function did not change. ${ }^{15}$

Lin et al. (2017) examined the effectiveness of VEDs and penile traction therapy (PTT) using an animal model. Both the VED and the PTT group had statistically significant reduction in penile curvature compared to the control group. Although the PTT group had a greater reduction in penile curvature, the VED group had greater erectile function preservation which they hypothesize was due to decreases in both TGF- $\beta 1$ and cell apoptosis. ${ }^{20} \mathrm{Li}$ et al. (2018) also used an animal model and found that VEDs can reduce fibrotic plaque size, although their fibrotic plaques were simulated by the injection of TGF- $\beta 1 .{ }^{21}$ Whether these animal models represent the human condition is not clear.

VEDs have been previously studied in combination with surgery and injections. Lue et al. (1999) instituted the use of a VED following circular venous grafting. Three patients who used the VED had an increase in penile length of two inches whereas the single patient who did not use the VED had a one-inch increase. Unfortunately, the number of participants is too low to draw any concrete conclusions other than that VEDs were well tolerated. Raheem et al. (2017) studied the effects of collagenase clostridium histolyticum $(\mathrm{CCH})$ in combination with VED therapy for 12 weeks. The 54 patients enrolled saw a mean $17^{\circ}$ improvement in curvature, ${ }^{22}$ similar to what has been reported for $\mathrm{CCH}$ alone. ${ }^{23}$

We examined the use of VED traction therapy to reduce penile curvature and any factors that might contribute to the efficacy of this treatment. The 20 participants who received VED therapy saw a statistically significant improvement in curvature of $23 \pm 16^{\circ}$; each patient using this treatment had a reduction in their penile curvature. The 33 untreated participants saw a $3.6 \pm 12^{\circ}$ reduction in penile curvature. Only 9 untreated participants saw a reduction in penile curvature, 20 saw no change, and 4 saw an increase in penile curvature during the study. Patient comorbidities/characteristics had no effect on outcomes. There were no adverse events reported in our study.

Like other studies examining VED therapy and PTT, measures of sexual function did not improve significantly in the treatment group. The untreated group had a significant reduction in SHIM score, indicating a decline in sexual function. While it is encouraging that we had significant reductions in penile curvature, it may not be as clinically relevant if there is no improvement in sexual function. We speculate that as our participants continue to use the VED for longer time periods, they may see a more substantial improvement in sexual function.

The body of evidence for PTT in the setting of PD shows comparable improvement in penile curvature to our results. ${ }^{24}$ VED therapy may be a better option for patients as it is easier to use and more comfortable ${ }^{25}$. Although the price of a VED can exceed the cost of a penile traction device. 
Our curvature data relied upon using a photograph taken at home and a protractor in the office. This method can be inaccurate as the three-dimensional curvature is projected onto a twodimensional image. We agree with Levine et al. (2003) that the use of a protractor is the most consistent and reliable technique. ${ }^{26}$

Our retrospective study reported results from only 53 patients at a single site. Participants in this study were selected if they opted not to pursue surgical or injectable management of PD which may have biased our study to include less severe cases of PD which were more amenable to non-invasive management. A randomized, single-blinded control trial would provide more substantial evidence for the use of VEDs in the setting of PD.

Data on the effectiveness of VED therapy for PD is scarce in the literature. More study is needed to further investigate the variables involved in VED therapy, for example: treatment duration, treatment course duration, and negative pressure requirements in the VED.

\section{Conclusions}

VED therapy is an effective, conservative method for reducing penile curvature. We found men with large initial penile curvatures had the greatest improvement in curvatures and the duration of $\mathrm{PD}$ and patient age did not affect the magnitude of penile curvature improvement.

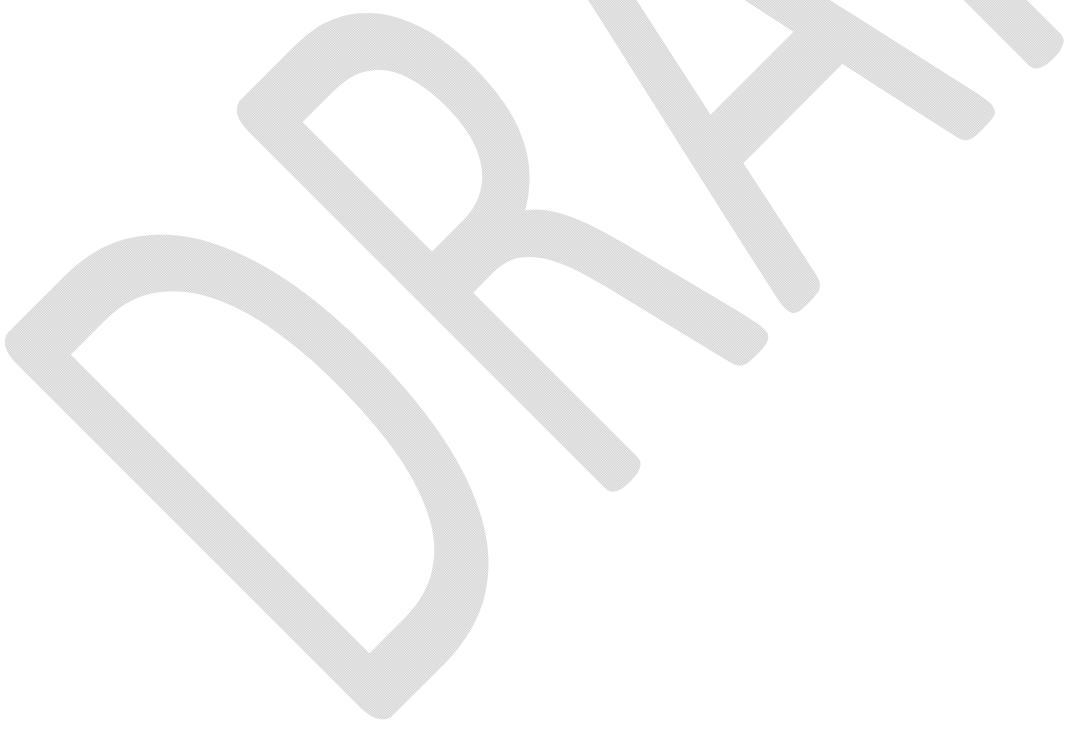




\section{References}

1. Stuntz M, Perlaky A, des Vignes F, et al: The Prevalence of Peyronie's Disease in the United States: A Population-Based Study. PLoS One 2016; 11: e0150157. Available at: https://doi.org/10.1371/journal.pone.0150157.

2. Nehra A, Alterowitz R, Culkin DJ, et al: Peyronie's disease: AUA guideline. J. Urol. 2015; 194: 745-753. Available at: http://dx.doi.org/10.1016/j.juro.2015.05.098.

3. Mulhall JP: Expanding the paradigm for plaque development in Peyronie's disease. Int $J$ Impot Res 2003; 15: S93-S102. Available at: http://dx.doi.org/10.1038/sj.ijir.3901082.

4. Somers KD and Dawson DM: Fibrin Deposition in Peyronie's Disease Plaque. J. Urol. 2016; 157: 311-315. Available at: http://dx.doi.org/10.1016/S0022-5347(01)65367-9.

5. Yafi FA, Pinsky MR, Sangkum P, et al: Therapeutic advances in the treatment of Peyronie's disease. Andrology 2015; 3: 650-660. Available at: http://dx.doi.org/10.1111/andr.12058.

6. Yafi FA, Pinsky MR, Stewart C, et al: The Effect of Duration of Penile Traction Therapy in Patients Undergoing Intralesional Injection Therapy for Peyronie's Disease. J. Urol. 2016; 194: 754-758. Available at: http://dx.doi.org/10.1016/j.juro.2015.03.092.

7. Hauck EW, Diemer T, Schmelz HU, et al: A critical analysis of nonsurgical treatment of Peyronie's disease. Eur. Urol. 2006; 49: 987-97. Available at: http://www.ncbi.nlm.nih.gov/pubmed/16698449, accessed September 7, 2016.

8. Abern MR, Larsen S and Levine LA: Combination of Penile Traction, Intralesional Verapamil, and Oral Therapies for Peyronie's Disease. J. Sex. Med. 2012; 9: 288-295. Available at: http://dx.doi.org/10.1111/j.1743-6109.2011.02519.x.

9. Smith JF, Walsh TJ, Conti SL, et al: Risk Factors for Emotional and Relationship Problems in Peyronie's Disease. J. Sex. Med. 2016; 5: 2179-2184. Available at: http://dx.doi.org/10.1111/j.1743-6109.2008.00949.x.

10. Rosen R, Catania J, Lue T, et al: Impact of Peyronie's Disease on Sexual and Psychosocial Functioning: Qualitative Findings in Patients and Controls. J. Sex. Med. 2016; 5: 1977-1984. Available at: http://dx.doi.org/10.1111/j.1743-6109.2008.00883.x.

11. Berookhim BM, Choi J, Alex B, et al: Deformity stabilization and improvement in men with untreated Peyronie's disease. BJU Int. 2014; 113: 133-136. Available at: http://dx.doi.org/10.1111/bju.12346.

12. Guillot-Tantay C, Phé V, Chartier-Kastler E, et al: Traitements médicaux et chirurgicaux des courbures de verge congénitales et acquises : revue de la littérature. Progrès en Urol. 2014; 24: 203-211. Available at: http://www.sciencedirect.com/science/article/pii/S1166708713006659.

13. Vardi Y, Levine LA, Chen J, et al: Controversies in Sexual Medicine: Is There a Place for Conservative Treatment in Peyronie's Disease? J. Sex. Med. 2009; 6: 903-909. Available at: http://dx.doi.org/10.1111/j.1743-6109.2009.01214.x.

14. Taylor F and Levine L: Peyronie?s disease. In: Textbook of Erectile Dysfunction,Second Edition. CRC Press 2008; pp 405-412. Available at: http://dx.doi.org/10.3109/9780203091807-54.

15. Raheem AA, Garaffa G, Raheem TA, et al: The role of vacuum pump therapy to mechanically straighten the penis in Peyronie's disease. BJU Int. 2010; 106: 1178-1180. 
Available at: http://dx.doi.org/10.1111/j.1464-410X.2010.09365.x.

16. Chung E and Brock G: Penile traction therapy and Peyronie's disease: a state of art review of the current literature. Ther. Adv. Urol. 2013; 5: 59-65. Available at: http://www.ncbi.nlm.nih.gov/pmc/articles/PMC3547530/.

17. Cappelleri JC and Rosen RC: The Sexual Health Inventory for Men (SHIM): a 5-year review of research and clinical experience. Int. J. Impot. Res. 2005; 17: 307-319.

18. Shindel AW, Bullock TL and Brandes S: Urologist Practice Patterns in the Management of Peyronie's Disease: A Nationwide Survey. J. Sex. Med. 2008; 5: 954-964. Available at: http://dx.doi.org/10.1111/j.1743-6109.2007.00674.x.

19. Sullivan J, Moskovic D, Nelson C, et al: Peyronie's disease: urologist's knowledge base and practice patterns. Andrology 2015; 3: 260-264. Available at: https://onlinelibrary.wiley.com/doi/abs/10.1111/andr.292.

20. Lin H, Liu C and Wang R: Effect of Penile Traction and Vacuum Erectile Device for Peyronie's Disease in an Animal Model. J. Sex. Med. 2017; 14: 1270-1276.

21. Li J, Wang S, Qin F, et al: Reduction in Peyronie's-like plaque size using a vacuum erection device in a rat model of Peyronie's disease via the TGF-beta/SMAD signalling pathway. Andrologia 2018; 50: e13051.

22. Abdel Raheem A, Capece M, Kalejaiye O, et al: Safety and effectiveness of collagenase clostridium histolyticum in the treatment of Peyronie's disease using a new modified shortened protocol. BJU Int. 2017; 120: 717-723.

23. Brimley SC, Yafi FA, Greenberg J, et al: Review of Management Options for ActivePhase Peyronie's Disease. Sex. Med. Rev. 2019; 7: 329-337.

24. Capoccia E and Levine LA: Contemporary Review of Peyronie's Disease Treatment. Curr. Urol. Rep. 2018; 19: 51.

25. Pahlajani G, Raina R, Jones S, et al: Vacuum erection devices revisited: its emerging role in the treatment of erectile dysfunction and early penile rehabilitation following prostate cancer therapy. J. Sex. Med. 2012; 9: 1182-1189.

26. Levine LA and Greenfield JM: Establishing a standardized evaluation of the man with Peyronie's disease. Int. J. Impot. Res. 2003; 15: S103. Available at: http://dx.doi.org/10.1038/sj.ijir.3901083. 
Figures and Tables

\begin{tabular}{|l|c|c|c|}
\hline Table 1. Patient characteristics presented as mean (standard deviation) or percentage \\
\hline Characteristics & $\begin{array}{c}\text { VED } \\
\text { group }\end{array}$ & $\begin{array}{c}\text { Untreated } \\
\text { group }\end{array}$ & p \\
\hline Age (years) & $54(10)$ & $58(11)$ & 0.104 \\
\hline Duration with PD (months) & $24(12)$ & $25(15)$ & 0.407 \\
\hline Initial curvature (deg) & $52(21)$ & $53(24)$ & 0.437 \\
\hline Followup duration (months) & $14(7)$ & $13(12)$ & 0.307 \\
\hline Diabetes (\%) & 5 & 12 & 0.097 \\
\hline Hypertension (\%) & 20 & 27 & 0.138 \\
\hline Dyslipidemia (\%) & 15 & 9 & 0.128 \\
\hline Smoker (\%) & 55 & 45 & 0.125 \\
\hline
\end{tabular}

None of the characteristics were found to be significantly different between groups. PD:

Peyronie's disease; VED: vacuum erection device.

\begin{tabular}{|l|c|c|c|c|c|c|c|}
\hline \multicolumn{7}{|l}{ Table 2. Mean (standard deviation) of measured variables } \\
\hline Variables & $\begin{array}{c}\text { VED } \\
(\mathbf{n = 2 0})\end{array}$ & $\begin{array}{c}\mathbf{\%} \\
\text { change }\end{array}$ & $\mathbf{p}^{*}$ & $\begin{array}{c}\text { Control } \\
(\mathbf{n = 3 3 )}\end{array}$ & $\begin{array}{c}\mathbf{\%} \\
\text { change }\end{array}$ & $\mathbf{p}^{*}$ & $\mathbf{p}^{\dagger}$ \\
\hline $\begin{array}{l}\text { Improvement } \\
\text { in penile } \\
\text { curvature }\end{array}$ & $23.0 \pm 16.0$ & -44 & $2.6 \times 10^{-6}$ & $3.6 \pm 12.0$ & -6.8 & 0.048 & $4.9 \times 10^{-6}$ \\
\hline $\begin{array}{l}\text { Change in } \\
\text { SHIM Score }\end{array}$ & $0.6 \pm 1.7$ & 3 & 0.072 & $-0.7 \pm 1.7$ & -4.4 & 0.018 & $6.8 \times 10^{-3}$ \\
\hline
\end{tabular}

${ }^{*}$ Measures the significance of change within each group. ${ }^{\dagger}$ Measures the significance between each group. SHIM: Sexual Health Inventory for Men. 